\title{
Deep level transient spectroscopy (DLTS) study of defects introduced in antimony doped Ge by $2 \mathrm{MeV}$ proton irradiation
}

\author{
C. Nyamhere ${ }^{\text {la }}$, A.G.M. Das ${ }^{\text {c }}$, F.D. Auret ${ }^{\mathrm{b}}$, A. Chawanda ${ }^{\mathrm{b}}$, C.A. Pineda- \\ $\operatorname{Vargas}^{\text {d.e }}$ and A. Venter ${ }^{\mathrm{a}}$ \\ ${ }^{a}$ Physics department, Nelson Mandela Metropolitan University, Port Elizabeth 6031, \\ South Africa \\ ${ }^{b}$ Department of Physics, University of Pretoria, Pretoria 0002, South Africa \\ ${ }^{c}$ School of Information Technology, Monash South Africa, Roodepoort 1725, South \\ Africa
}

${ }^{d}$ iThemba LABS, Somerset West, 7129, South Africa

${ }^{e}$ Faculty of Health \& Wellness Sciences C.P.U.T.,PO Box 1906, Bellville, 7535

\begin{abstract}
Deep level transient spectroscopy (DLTS), and Laplace-DLTS have been used to investigate the defects created in Sb doped Ge after irradiation with $2 \mathrm{MeV}$ protons having a fluence of $1 \times 10^{13}$ protons $/ \mathrm{cm}^{2}$. The results show that proton irradiation resulted in primary hole traps at $E_{\mathrm{V}}+0.15 \mathrm{eV}$ and $E_{\mathrm{V}}+0.30 \mathrm{eV}$ and electron traps, at $E_{\mathrm{C}}-0.38 \mathrm{eV}, E_{\mathrm{C}}-0.32 \mathrm{eV}, E_{\mathrm{C}}-0.31 \mathrm{eV}, E_{\mathrm{C}}-0.22 \mathrm{eV}, E_{\mathrm{C}}-0.20 \mathrm{eV}, E_{\mathrm{C}}-0.17 \mathrm{eV}$, $E_{\mathrm{C}}-0.15 \mathrm{eV}$ and $E_{\mathrm{C}}-0.04 \mathrm{eV}$. Defects observed in this study are compared with those introduced in similar samples after $\mathrm{MeV}$ electron irradiation reported earlier. $E_{\mathrm{C}}$ - $0.31 \mathrm{eV}, E_{\mathrm{C}}-0.17 \mathrm{eV}$ and, $E_{\mathrm{C}}-0.04 \mathrm{eV}$, and $E_{\mathrm{V}}+0.15 \mathrm{eV}$ were not observed previously in similar samples after high energy irradiation. Results from this study suggest that although similar defects are introduced by electron and proton irradiation, traps introduced by the latter are dose dependent.
\end{abstract}

Keywords: Ge, defects, proton irradiation, electron irradiation, DLTS, L-DLTS.

\footnotetext{
${ }^{1}$ Corresponding Author: C. Nyamhere, email: s210239522@live.nmmu.ac.za, address, Nelson Mandela Metropolitan University, Port Elizabeth, 6031, South Africa
} 


\section{INTRODUCTION}

Germanium (Ge) is known for its superior electron and hole mobility at low electric fields [1] and consequently the material is an excellent candidate for the development of high efficiency complimentary metal-oxide-semiconductor (CMOS) device. The renewed interest in Ge for electronic applications inevitably requires identifying and understanding the electrical properties of defects introduced unintentional during various processing stages or after high-energy particle irradiation.

High energy protons are an important component of solar radiation. It is consequently important to investigate the nature of defects it introduces in semiconductors if efficient and reliable devices for space applications are to be considered. There have been several reports on defects introduced by high energy particles, in particular electron irradiation in Ge [2-14]. The defects introduced during electron beam deposition of Pt Schottky contacts [2] and the implantation of $n$-Ge by different ions $[3,4]$ have been investigated extensively. It is generally believed that heavy ions create extended defects and more complex traps when compared to irradiation with light particles such as electrons. These traps may enhance or degrade the performance of devices fabricated thereon. A literature survey suggests that high energy proton irradiation studies of defects in $n$-Ge have not been as comprehensive and/or extensive studied as is the case with electrons. This may be due to the notion that similar defects are usually created by proton and electron irradiation. It has been shown recently that high energy electron and low dose proton irradiation usually introduce similar defects in Ge [4]. However, increased proton irradiation doses usually lead to the introduction of different and more complex defects.

In this study defects created after $\mathrm{MeV}$ proton irradiation are compared to those introduced by $\mathrm{MeV}$ electrons in similar samples.

\section{EXPERIMENTAL PROCEDURE}

Bulk grown (100) $n$-type Ge supplied by Umicore, doped with antimony (Sb) to a density of about $2 \times 10^{15} \mathrm{~cm}^{-3}$ was used in this study. Before metallization, samples $1 \mathrm{~cm} \times 0.5 \mathrm{~cm}$ in size were first degreased and then etched in a mixture of $\mathrm{H}_{2} \mathrm{O}_{2}: \mathrm{H}_{2} \mathrm{O}$ (1:5) for 1 minute. Immediately after cleaning ohmic contacts were formed by depositing a $130 \mathrm{~nm} \mathrm{AuSb}(0.6 \% \mathrm{Sb})$ layer on the backside of the sample. This was 
followed by annealing at $350{ }^{\circ} \mathrm{C}$ in an argon (Ar) atmosphere for 10 minutes to minimize the contact resistance. The samples were again briefly etched as described earlier before circular ( $0.6 \mathrm{~mm}$ in diameter and $100 \mathrm{~nm}$ thick) Pd Schottky barrier diodes (SBDs) were resistively evaporated onto the front surface of the samples The samples were hereafter irradiated with $2 \mathrm{MeV}$ protons at a fluence of $1 \times 10^{13} \mathrm{~cm}^{-2}$ at room temperature. The proton irradiation was performed at iTemba labs, South Africa using a cyclotron accelerator. Room temperature current-voltage $(I-V)$ and capacitance-voltage $(C-V)$ measurements were used to assess the SBD quality and the free carrier concentrations respectively of the material. The defects introduced were characterized by DLTS and Laplace-DLTS [5,6]. The 'signatures' of radiation induced defects (i.e. energy position in band gap relative to the conduction band and valence band for the electron traps and hole traps, respectively, $E_{T}$, and their apparent capture cross section, $\sigma_{\mathrm{a}}$ ), were determined from Arrhenius plots of $\ln \left(\mathrm{T}^{2} / \mathrm{e}\right)$ vs. 1000/T. Here, e represents either the hole or electron emission rate, and $T$ is the measurement temperature in Kelvin. In order to gain a better understanding of the observed defects the samples were isochronally annealed (10 minutes) in $\mathrm{Ar}$ in the temperature range $25^{\circ} \mathrm{C}-300^{\circ} \mathrm{C}$ in steps of $50^{\circ} \mathrm{C}$. I- $V, C-V$, DLTS and L-DLTS measurements were performed after each annealing cycle.

\section{RESULTS AND DISCUSSION}

Next, the electronic properties and annealing behavior of the defects created by proton irradiation are presented. These results are compared to that obtained in the same material after electron irradiation reported previously [8].

\subsection{Electron traps observed after proton irradiation}

Fig. 1 depicts DLTS spectra of the Sb doped $n$-Ge studied after $2 \mathrm{MeV}$ proton irradiation. Evidently, proton irradiation introduced a number of electron traps $E_{\mathrm{p}}(0.38), E_{\mathrm{p}}(0.32), E_{\mathrm{p}}(0.31), E_{\mathrm{p}}(0.22), E_{\mathrm{p}}(0.20), E_{\mathrm{p}}(0.17), E_{\mathrm{p}}(0.15)$, and $E_{\mathrm{p}}(0.04)$ as is observed in Fig.1 (b). In the nomenclature used, ' $E$ ' denotes electron traps, subscript 'p', proton irradiation and the number in brackets, the activation enthalpy. It should be noted that the reference sample Fig. 1(a) did not contain any defects in detectable quantities [7-8]. Fig. 2 shows Arrhenius plots for the electron traps observed in Fig.1 while all the defect electronic properties $\left(E_{\mathrm{T}}, \sigma_{a}\right.$ and possible defect origins) are listed 
in Table 1. MeV electrons and protons are known to produce vacancy-interstitial (V-I) pairs distributed uniformly along the incident ion path, hence the most dominant trap after proton irradiation is the $E_{\mathrm{p}}(0.38)$ which is the --/- charge state of the V-Sb $(E$ center). A depth profile of this defect is depicted in Fig.3 and shows a slowly decreasing concentration with depth as expected for high energy proton irradiation. Generally, the origin of most electron traps introduced in n-Ge by high energy particle irradiation is still unresolved. $E_{\mathrm{p}}(0.22), E_{\mathrm{p}}(0.20)$, and $E_{\mathrm{p}}(0.15)$ have all been attributed to $\mathrm{Sb}$ and/or interstitial (I) related complexes by different authors as indicated in Table.1, but the origin of $E_{\mathrm{p}}(0.32)$ is still unclear. $E_{\mathrm{p}}(0.31)$ might be similar to $\mathrm{E}_{0.31}$ which has been observed by Auret et al [9,10] after low energy Ar inductively coupled plasma (ICP) etching. In this study, $E_{\mathrm{p}}(0.17)$ and $E_{\mathrm{p}}(0.04)$ were observed after proton irradiation but not after electron irradiation. A trap similar to $E_{\mathrm{p}}(0.04)$ was observed after electron irradiation of $\mathrm{Sb}$ doped $n$-Ge (with doping concentration of $\left.2.2 \times 10^{14} \mathrm{~cm}^{-3}\right)$ [11]. The annealing studies showed that $E_{\mathrm{p}}(0.38)$ anneals at $200{ }^{\circ} \mathrm{C}$ which is expected for the $E$-center, and $E_{\mathrm{p}}(0.32)$ is removed at around $300{ }^{\circ} \mathrm{C}$.

\subsection{Hole traps after proton irradiation}

Fig. 4 (a) shows DLTS spectra of the two hole traps $H_{\mathrm{p}}(0.15)$ and $H_{\mathrm{p}}(0.30)$ introduced in $n$-Ge by proton irradiation. The electron properties extracted from the Arrhenius plots are summarized in Table.2. The hole trap $H_{\mathrm{p}}(0.30)$, identified as the single acceptor charge state of the $\mathrm{V}-\mathrm{Sb} . H_{\mathrm{p}}(0.15)$ has not been observed in similar samples after electron irradiation, however this trap was observed after electron beam deposition of Pt Schottky contacts [2,9]. In oxygen rich p-type Ge samples, Pearton et al. observed a trap at $E_{\mathrm{V}}+0.23$ after high energy gamma irradiation which was attributed to oxygen related complex [12], whereas Ito and Cobertt observed a hole trap at $\mathrm{E}_{\mathrm{V}}+0.17$ after hydrogen implantation [13]. Whether $H_{\mathrm{p}}(0.15)$ observed in this experiment could be ascribed to either oxygen or hydrogen related complexes is subject to speculation. Fig. 5 depicts the temperature dependent evolution of the DLTS signal for hole traps observed in Fig. 4 subsequent to isochronal annealing in the temperature range $100{ }^{\circ} \mathrm{C}-300{ }^{\circ} \mathrm{C}$. It is clear from Fig. 5 that $H_{\mathrm{p}}(0.27)$ is only observed after annealing at $200{ }^{\circ} \mathrm{C}$, suggesting that this trap is thermally generated. This compares well with what has been observed for electron irradiated $n$-Ge. Evidently, $H_{\mathrm{p}}(0.30)$ disappeared after annealing at $200{ }^{\circ} \mathrm{C}$ while $H_{\mathrm{p}}(0.27)$ reached its maximum concentration at the same temperature. This is further proof that these two 
traps are indeed related and possibly point to a higher order $\mathrm{V}-\mathrm{Sb}$ center, i.e. $\mathrm{V}-\mathrm{Sb}_{2}$ [14].

\section{SUMMARY}

Defects in antimony doped Ge after $2 \mathrm{MeV}$ proton irradiation have been characterized and compared with those observed in the same material after $\mathrm{MeV}$ electron irradiation. $E_{\mathrm{p}}(0.38)$ is the most prominent electron trap. $H_{\mathrm{p}}(0.30)$ evolves into $\mathrm{H}(0.27)$ following annealing in the temperature range $100{ }^{\circ} \mathrm{C}-300^{\circ} \mathrm{C}$. These defects are believed to be related to the double and single acceptor charge state of the $E$ center respectively. Most of the defect levels observed in this study were also observed after $\mathrm{MeV}$ electron irradiation except for the traps $E_{\mathrm{p}}(0.17)$ and $E_{\mathrm{p}}(0.04)$. This confirms that electron irradiation and proton irradiation do not result in same set of defects being introduced. High doses of protons introduce complex defects.

\section{ACKNOWLEDGEMENTS}

This work has been made possible by financial assistance from the South African National Research Foundation and Monash University, South Africa.

\section{REFERENCES}

[1] Germanium Silicon, Physics and Materials, Semiconductor and Semi-metals Vol.56, edited by Hull and J. C. Bean (Academic, San Diego, 1999).

[2] F. D. Auret, W. E Meyer, S. Coelho and M. Hayes, Appl. Phys. Lett. 88 (2006) 242110.

[3] F. D. Auret, P. J. Janse van Rensburg, M. Hayes, J. M. Nel, W. E Meyer, S. Decoster, V. Matias and A. Vantomme, Appl. Phys. Lett. 89 (2006) 152123.

[4] V.P Markvevich, S. Bernardini, I.D. Hawkins, A.R. Peaker, V.I. Kolkovsky, A. Nylandsted Larsen, and L. Dobaczewski, Mater Sci. in Semicond. Process 11 (2008) 354 .

[5] L. Dobaczewski, P. Kaczor, I. D. Hawkins, A. R Peaker, J. Appl. Phys. 76 (1994) 194.

[6] L. Dobaczewski, A. R Peaker, K. B. Nielsen, J. Appl. Phys. 96 (2004) 4689. 
[7] J. Fage-Pedersen, A. Nylandsted Larsen, and A. Mesli, Phys. Rev. B. 62 (2000) 10116.

[8] Cloud Nyamhere, F.D. Auret, A.G.M. Das, A. Chawanda. Physica B 401-402 499 (2007).

[9] F.D. Auret, S.M.M. Coelho, G. Myburg, P.J. Janse van Rensburg and W.E Meyer, Thin Solid Films 518 (2010) 2485.

[10] F.D. Auret, S.M.M. Coelho, G. Myburg, P.J. Janse van Rensburg and W.E Meyer, Physica B 404 (2009) 4376.

[11] C. Nyamhere, Ph.D Thesis, University of Pretoria, 2009.

[12] S.J. Pearton, A.J. Tavendale, J.M. Kahn, E.E. Haller, Radiation Effects and Defects in Solids 81 (1984) 293

[13] K. Ito and J. W. Corbett, Japanese J. of Appl. Phys. 22 (1983) L724.

[14] V.P. Markervich, Mater Sci. in Semicond. Process 9 (2006) 589.

List of figures

Fig. 1 DLTS spectra for (a) un-irradiated sample (reference), and (b) electron traps after $2 \mathrm{MeV}$ proton irradiation of $n$-Ge. The spectra were recorded at a quiescent reverse bias of $1 \mathrm{~V}$ and a pulse voltage of $+0.5 \mathrm{~V}$ superimposed on the reverse bias. The pulse width was $1 \mathrm{~ms}$ and the rate window $80 \mathrm{~s}^{-1}$.

Fig. 2 Arrhenius plots of electron traps introduced in $n$-Ge after proton irradiation (filled circles) and electron irradiation (empty triangles) reproduced from reference.8.

Fig. 3 Depth profile of $E_{\mathrm{p}}(0.38)$ in $n$-Ge after proton irradiation. The profile was recorded at reverse bias of $-2 \mathrm{~V}$ and temperature of $200 \mathrm{~K}$.

Fig. 4 DLTS spectra of holes traps introduced in $n$-Ge after $2 \mathrm{MeV}$ proton irradiation for (a) as-irradiated and after annealing at (b) $100^{\circ} \mathrm{C}$, (c) $150^{\circ} \mathrm{C}$, (d) $200^{\circ} \mathrm{C}, 250^{\circ} \mathrm{C}$ and $300^{\circ} \mathrm{C}$. The spectra were recorded at a quiescent reverse bias of $1 \mathrm{~V}$, pulse voltage of $+3 \mathrm{~V}$ superimposed on the reverse bias. The pulse width was $1 \mathrm{~ms}$ and the rate window $80 \mathrm{~s}^{-1}$. 
Fig. 5 Annealing behaviour of hole traps introduced in $n$-Ge after proton irradiation.

Fig. 1

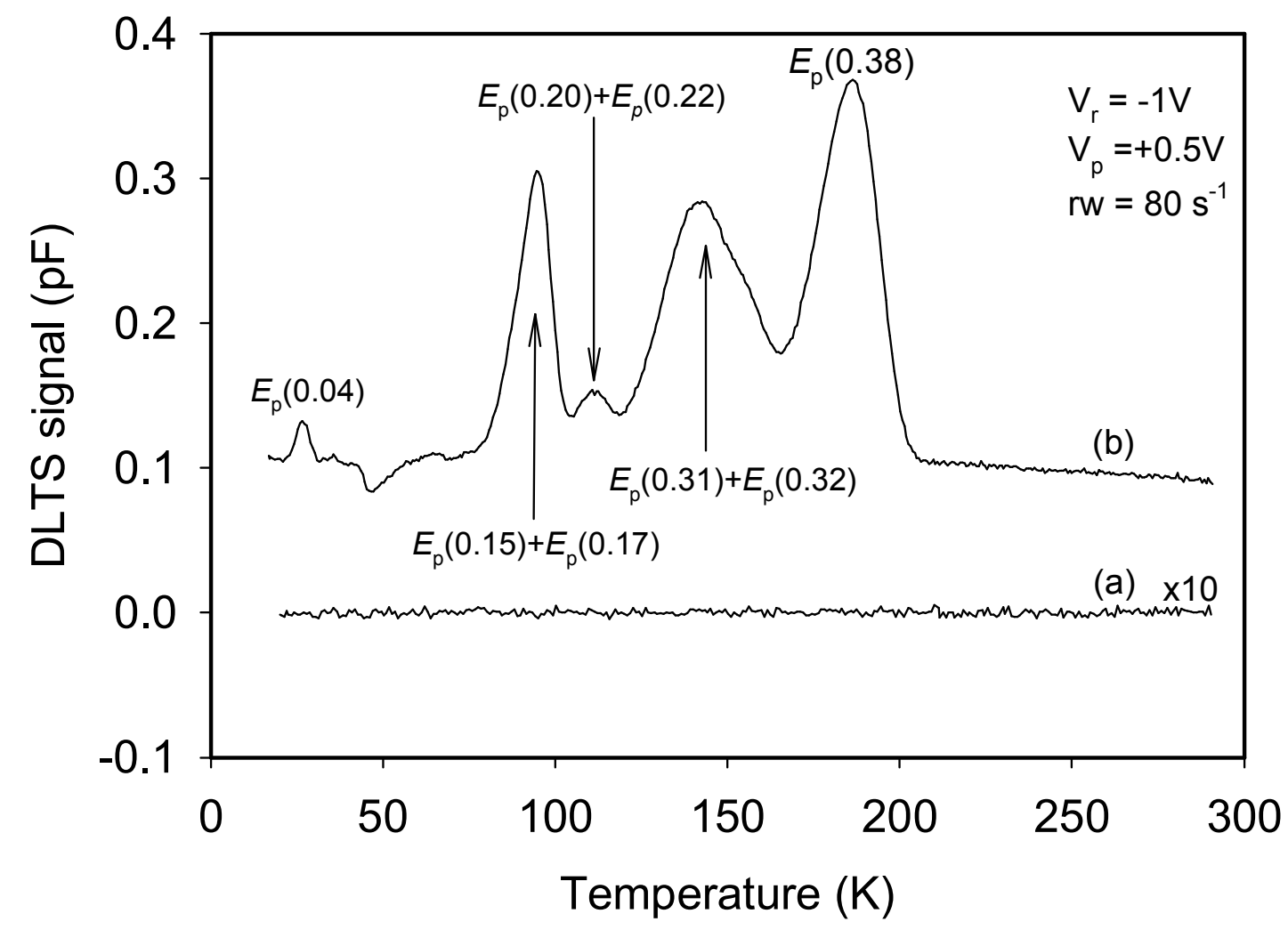


Fig. 2

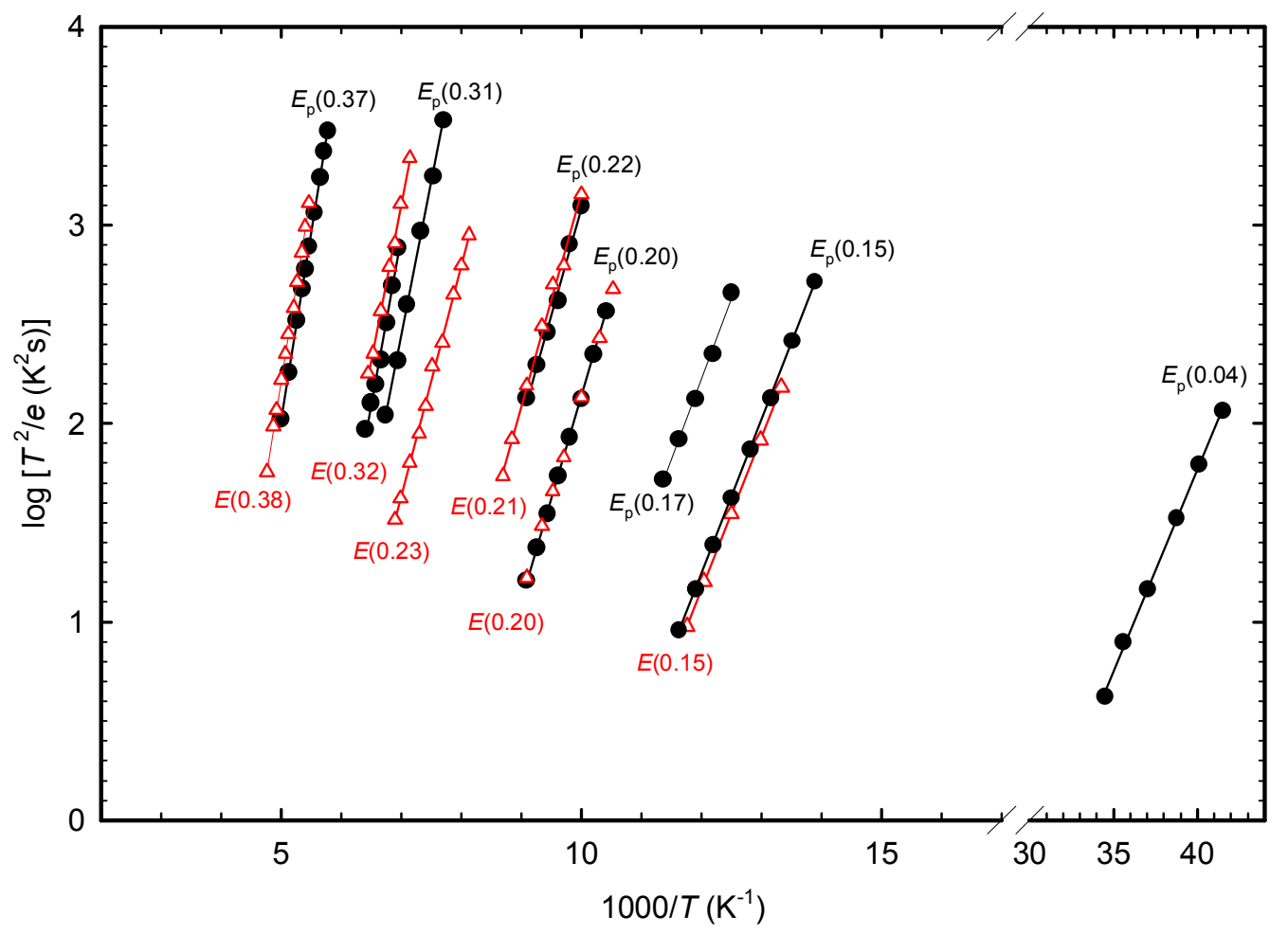


Fig. 3

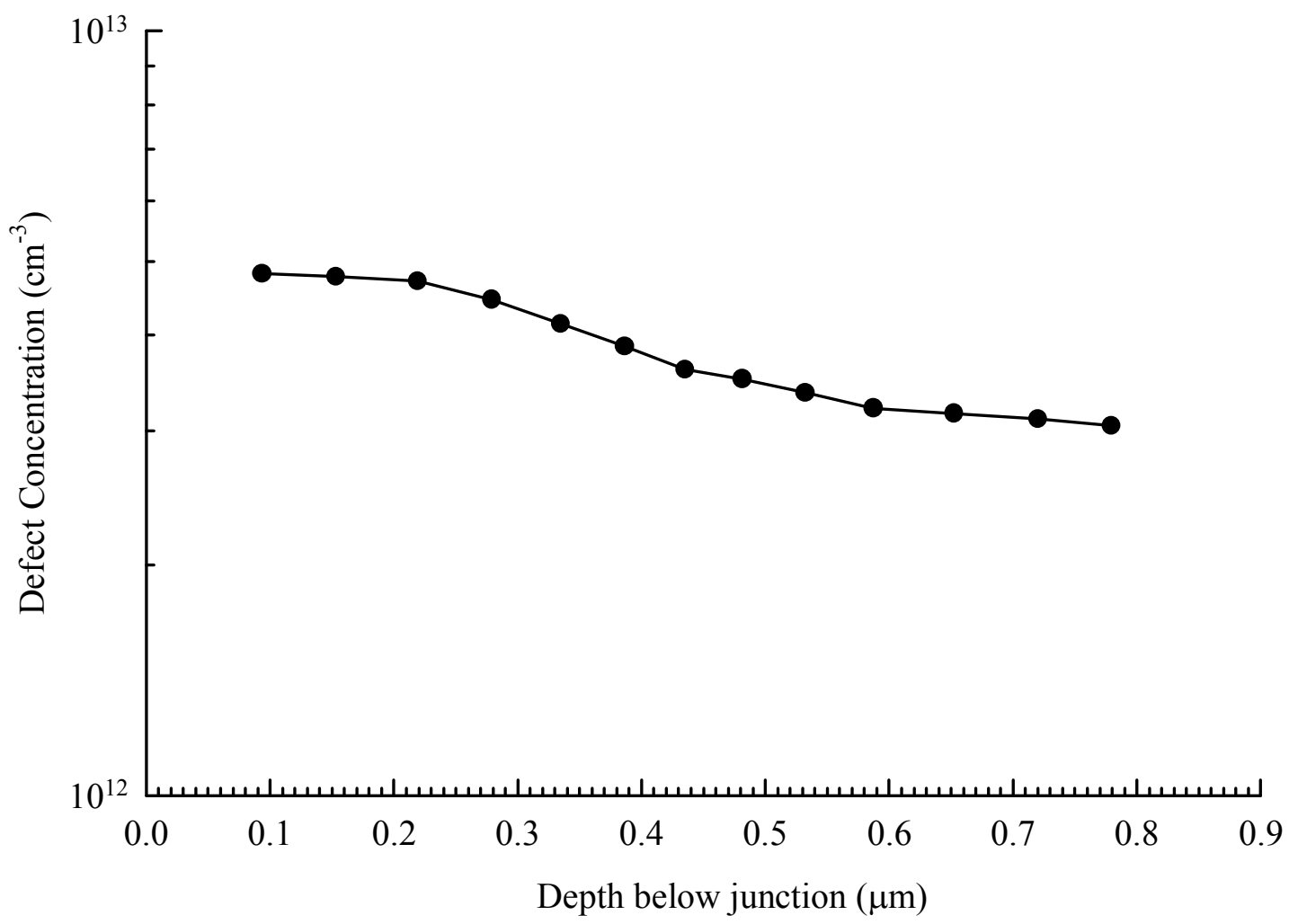


Fig. 4

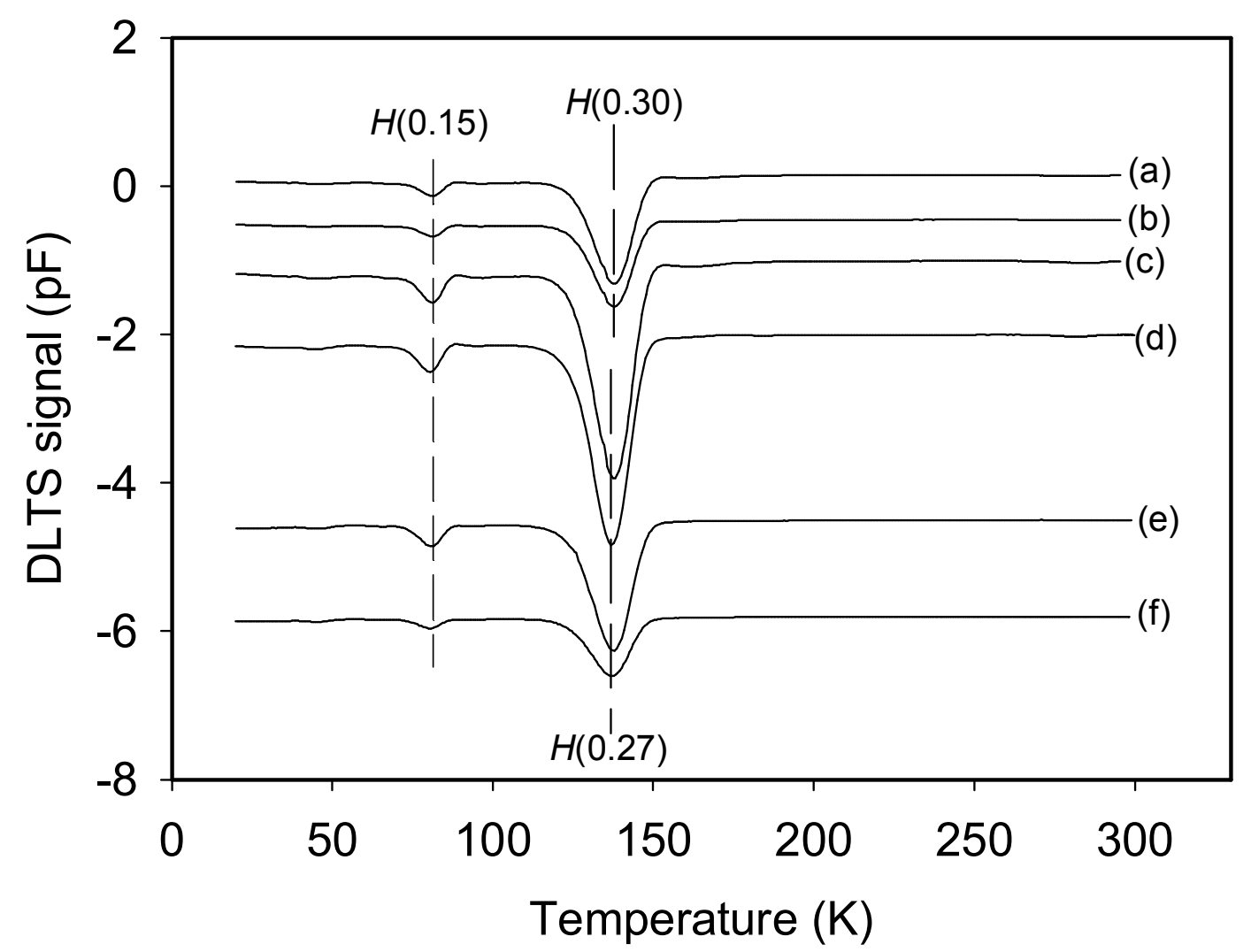


Fig. 5

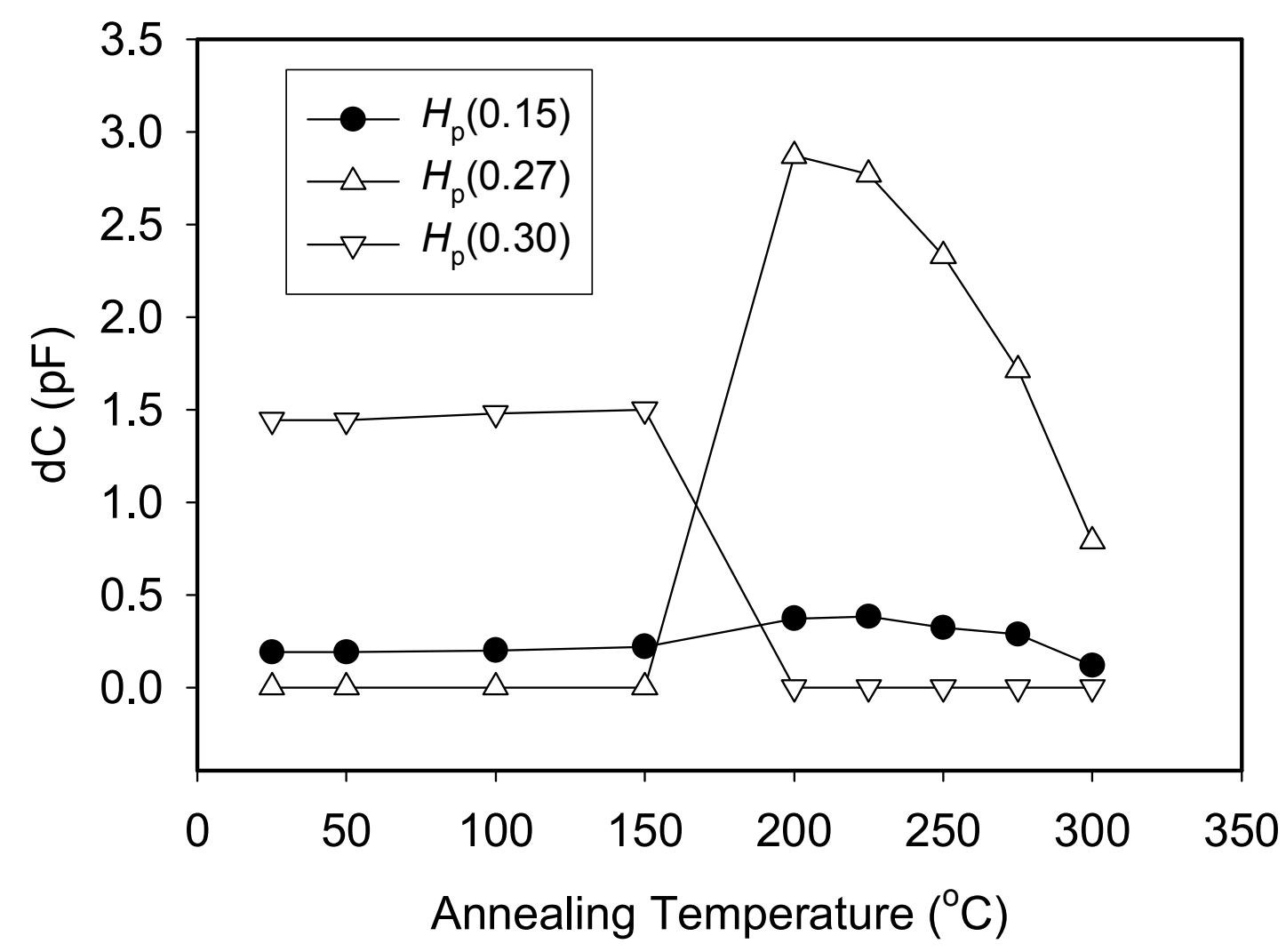


Table. 1: Electronic properties of electron traps introduced in $n$ - Ge after proton irradiation. These traps are compared with traps introduced by electron irradiation in the same material previously reported [.8.]

\begin{tabular}{|c|c|c|c|c|c|c|}
\hline Defect & $E_{\mathrm{T}}(\mathrm{eV})$ & $\sigma_{\mathrm{a}}\left(\mathrm{cm}^{-2}\right)$ & Defect & $E_{\mathrm{T}}(\mathrm{eV})$ & $\sigma_{\mathrm{a}}\left(\mathrm{cm}^{-2}\right)$ & Defect identity \\
\hline \multicolumn{3}{|c|}{$\begin{array}{l}\text { After proton irradiation } \\
\text { (This study) }\end{array}$} & \multicolumn{4}{|c|}{ After electron irradiation (from ref.8) } \\
\hline$E_{\mathrm{p}}(0.38)$ & $E_{\mathrm{C}}-0.38$ & $6.7 \times 10^{-14}$ & $E(0.38)$ & $E_{\mathrm{C}}-0.38$ & $6.1 \times 10^{-14}$ & V-Sb (--/-) $[2,6-11]$ \\
\hline$E_{\mathrm{p}}(0.32)$ & $E_{\mathrm{C}}-0.32$ & $3.3 \times 10^{-13}$ & $E(0.31)$ & $E_{\mathrm{C}}-0.31$ & $3.1 \times 10^{-13}$ & $\mathrm{~V}-\mathrm{Sb}(-/ 0)[2,3,7]$ \\
\hline$E_{\mathrm{p}}(0.31)$ & $E_{\mathrm{C}}-0.31$ & $7.4 \times 10^{-13}$ & --- & --- & --- & $?[9,10]$ \\
\hline--- & --- & --- & $E(0.23)$ & $E_{\mathrm{C}}-0.23$ & $9.7 \times 10^{-15}$ & $\mathrm{Sb}, \mathrm{I}$ related $[2,3,7]$ \\
\hline$E_{\mathrm{p}}(0.22)$ & $E_{\mathrm{C}}-0.22$ & $1.6 \times 10^{-13}$ & $E(0.21)$ & $E_{\mathrm{C}}-0.21$ & $1.1 \times 10^{-13}$ & $\mathrm{Sb}$, I related $[2,3,7]$ \\
\hline$E_{\mathrm{p}}(0.20)$ & $E_{\mathrm{C}}-0.20$ & $2.0 \times 10^{-13}$ & $E(0.20)$ & $E_{\mathrm{C}}-0.20$ & $2.3 \times 10^{-13}$ & $\mathrm{Sb}$, I related $[2,3,7]$ \\
\hline$E_{\mathrm{p}}(0.17)$ & $E_{\mathrm{C}}-0.17$ & $2.3 \times 10^{-13}$ & --- & --- & --- & $?$ \\
\hline$E_{\mathrm{p}}(0.15)$ & $E_{\mathrm{C}}-0.15$ & $3.5 \times 10^{-13}$ & $E(0.15)$ & $E_{\mathrm{C}}-0.15$ & $3.3 \times 10^{-13}$ & $\mathrm{Sb}$, I related $[2,3,7]$ \\
\hline$E_{\mathrm{p}}(0.04)$ & $E_{\mathrm{C}}-0.04$ & $7.0 \times 10^{-13}$ & --- & --- & --- & I-related [11] \\
\hline
\end{tabular}


Table.2: Electronic properties of defects introduced in $n$-Ge after proton irradiation.

\begin{tabular}{|c|c|c|c|c|c|c|}
\hline Defect & $E_{\mathrm{T}}(\mathrm{eV})$ & $\sigma_{\mathrm{a}}\left(\mathrm{cm}^{-2}\right)$ & Defect & $E_{\mathrm{T}}(\mathrm{eV})$ & $\sigma_{\mathrm{a}}\left(\mathrm{cm}^{-2}\right)$ & Defect identity \\
\hline \multicolumn{3}{|c|}{$\begin{array}{l}\text { After proton irradiation } \\
\text { (This study) }\end{array}$} & & \multicolumn{3}{|c|}{ After electron irradiation (from ref.8) } \\
\hline--- & --- & --- & $H(0.09)$ & $E_{\mathrm{V}}-0.09$ & $2.9 \times 10^{-12}$ & $\mathrm{~V}-\mathrm{Sb}^{(+/ 0)}[10,12]$ \\
\hline$H_{\mathrm{p}}(0.15)$ & $E_{\mathrm{V}}-0.15$ & $6.1 \times 10^{-14}$ & --- & --- & -- & $\begin{array}{l}\text { O, H related } \\
{[9,12,13]}\end{array}$ \\
\hline$H_{\mathrm{p}}(0.30)$ & $E_{\mathrm{V}}-0.30$ & $7.0 \times 10^{-13}$ & $H(0.30)$ & $E_{\mathrm{V}}-0.30$ & $4.0 \times 10^{-12}$ & $\mathrm{~V}-\mathrm{Sb}^{(0 /-)}[2,6-8.10]$ \\
\hline$H_{\mathrm{p}}(0.27)$ & $E_{\mathrm{V}}-0.27$ & $1.5 \times 10^{-13}$ & $H(0.27)$ & $E_{\mathrm{V}}-0.27$ & $4.6 \times 10^{-13}$ & $\mathrm{~V}-\mathrm{Sb}_{2}[14]$ \\
\hline
\end{tabular}

